\title{
Water immersion of dogs close to the time of topical fluralaner treatment does not reduce efficacy against a subsequent experimental challenge with Rhipicephalus sanguineus (sensu lato)
}

\author{
Heide Dongus ${ }^{1}$, Leon Meyer ${ }^{2}$ and Rob Armstrong ${ }^{3 *}$ (i)
}

\begin{abstract}
Background: Fluralaner is a novel systemic ectoparasiticide for dogs and cats providing immediate and persistent flea- and tick-control after a single topical dose. Prescribing directions recommend waiting $72 \mathrm{~h}$ following topical administration before immersing dogs in water. The objective of this study was to determine whether water immersion immediately prior to treatment or earlier than $72 \mathrm{~h}$ post-treatment reduced subsequent treatment efficacy.

Methods: Forty $(n=40)$ dogs were blocked on tick carrying capacity into 5 experimental groups and all but one of the groups (untreated control) were treated topically with fluralaner (Bravecto ${ }^{\oplus}$ Spot-On Solution, Merck Animal Health, Madison, NJ, USA) at the commercial dose. Three of the four remaining groups were immersed in $38-40^{\circ} \mathrm{C}$ water for a $5 \mathrm{~min}$ bath - either $1 \mathrm{~h}$ before treatment; $12 \mathrm{~h}$ after treatment; or $24 \mathrm{~h}$ after treatment. Seven days after treatment all dogs were challenged with 50 Rhipicephalus sanguineus (sensu lato) ticks and after $24 \mathrm{~h}$ attached ticks were counted and removed.
\end{abstract}

Results: Efficacies (compared to the untreated control group) were: $99.3 \%$ for no water immersion; $99.6 \%$ for immersion $1 \mathrm{~h}$ before treatment; 99.3\% for immersion $12 \mathrm{~h}$ after treatment; and, 100\% for immersion $24 \mathrm{~h}$ after treatment.

Conclusions: Water immersion of dogs around the time of topical fluralaner administration did not reduce subsequent systemic acaricidal efficacy.

Keywords: Bathing, Bravecto, Dog, Fluralaner, Rhipicephalus sanguineus, Water

\section{Background}

Fluralaner is a novel isoxazoline class compound that provides fast and persistent insecticidal and acaricidal efficacy in several formulations for dogs or cats [1]. Topically administered fluralaner is absorbed transdermally following administration [2], and a single dose provides 12 weeks of systemic control against multiple flea and tick species [1]. This insecticidal and acaricidal efficacy is not reduced by water and shampoo exposure after $72 \mathrm{~h}$ following treatment [3].

\footnotetext{
* Correspondence: robert.armstrong@merck.com

${ }^{3}$ Merck Animal Health, 2 Giralda Farms, Madison, NJ, USA

Full list of author information is available at the end of the article
}

Veterinarians and/or dog owners may inadvertently immerse a dog in water within $72 \mathrm{~h}$ of treatment, or a dog may make its own choice to get wet, in spite of the precaution in the prescribing information [1]. Another possibility is that dogs bathed shortly before treatment may still have wet skin and hair at the time of treatment. The objective of this study was to determine whether either of these situations reduces subsequent acaricidal efficacy of topically administered fluralaner.

\section{Methods}

Forty $(n=40)$ healthy mixed-breed dogs that had not received prior insecticide or acaricide treatment for at least 
12 weeks were ranked on Rhipicephalus sanguineus (sensu lato) carrying capacity in a pre-treatment tick challenge and then randomly blocked into five groups (Table 1) without regard to gender. Four groups of dogs were treated with topical fluralaner (Bravecto Spot-On Solution, MSD Animal Health, Madison, NJ, USA) at the recommended label dose $(25-56 \mathrm{mg} / \mathrm{kg}$ ) based on the dog's weight. In this study, dogs weighing between 10 and $20 \mathrm{~kg}$ received $500 \mathrm{mg}$ fluralaner and dogs weighing between 20 and $40 \mathrm{~kg}$ received $1000 \mathrm{mg}$ fluralaner. Three of these groups were also immersed for 5 min in fresh lukewarm $\left(38-40{ }^{\circ} \mathrm{C}\right.$ ) water (using new water for each immersion time point) $1 \mathrm{~h}$ before, $12 \mathrm{~h}$ after, or $24 \mathrm{~h}$ after topical fluralaner treatment (Table 1). Seven days after topical fluralaner administration, all dogs in all groups were challenged with 25 adult male and 25 adult female unfed $R$. sanguineus (s.l.) ticks. The dogs were sedated for approximately $1 \mathrm{~h}$ and placed in an infestation chamber to reduce stress to the dog and to facilitate tick infestations by allowing ticks to attach. After $24 \mathrm{~h}$, forceps were used to remove and count all ticks from all dogs.

Efficacy (\%) was calculated by comparing mean tick numbers (arithmetic means were used for all calculations) on each treated group with mean tick numbers on the untreated control group using the formula $100 \times$ $(\mathrm{MC}-\mathrm{MT}) / \mathrm{MC}$, where $\mathrm{MC}$ is the mean number of live attached ticks on untreated control dogs and MT is the mean number of total live attached ticks on dogs in each fluralaner treated group. The experimental unit was the individual $\operatorname{dog}$ and the groups were compared using an ANOVA (SAS Proc GLM procedure) with a treatment effect on both untransformed and logarithmic transformed tick (count +1 ) data.

\section{Results}

The mean acaricidal efficacy of topical fluralaner in all of the treated groups was between $99.3 \%$ and $100 \%$ (Table 2). There were no significant differences between the number of ticks on any fluralaner treated group (all $P$-values

Table 1 Treatments of five groups of dogs to evaluate the impact on efficacy of water immersion close to the time of topical fluralaner treatment

\begin{tabular}{ll}
\hline Group $(n=8)$ & Treatment \\
\hline Untreated control & No treatment and no water immersion \\
Positive control & $\begin{array}{l}\text { Treatment with topical fluralaner and } \\
\text { no water immersion }\end{array}$ \\
$\begin{array}{l}\text { Pre-treatment } \\
\text { immersion }\end{array}$ & $\begin{array}{l}\text { water immersion } 1 \mathrm{~h} \text { before treatment } \\
\text { Post-treatment }\end{array}$ \\
immersion $(12 \mathrm{~h})$ & Treatment with topical fluralaner followed \\
Post treatment & by water immersion after $12 \mathrm{~h}$ \\
immersion $(24 \mathrm{~h})$ & Treatment with topical fluralaner followed \\
\hline
\end{tabular}

Table 2 Acaricidal efficacy (24 h) against Rhipicephalus sanguineus (sensu lato) on dogs 7 days after topical fluralaner treatment and water immersion at various times

\begin{tabular}{|c|c|c|c|c|}
\hline Treatment & $\begin{array}{l}\text { Acaricidal } \\
\text { efficacy (\%) }\end{array}$ & $\begin{array}{l}P \text {-value vs } \\
\text { untreated } \\
\text { control }\end{array}$ & $\begin{array}{l}F_{(4,35)} \text { value } \\
\text { vs untreated } \\
\text { control }\end{array}$ & $\begin{array}{l}\text { Live attached } \\
\text { ticks } \\
\text { (mean } \pm \text { SD) }\end{array}$ \\
\hline Topical fluralaner & 99.3 & $<0.0001$ & 98.02 & $0.3 \pm 0.5$ \\
\hline No treatment & na & na & na & $34.5 \pm 9.8$ \\
\hline $\begin{array}{l}\text { Water immersion } \\
1 \mathrm{~h} \text { before topical } \\
\text { fluralaner treatment }\end{array}$ & 99.6 & $<0.0001$ & 98.02 & $0.1 \pm 0.4$ \\
\hline $\begin{array}{l}\text { Water immersion } \\
12 \mathrm{~h} \text { after topical } \\
\text { fluralaner treatment }\end{array}$ & 99.3 & $<0.0001$ & 98.02 & $0.3 \pm 0.7$ \\
\hline $\begin{array}{l}\text { Water immersion } \\
24 \mathrm{~h} \text { after topical } \\
\text { fluralaner treatment }\end{array}$ & 100 & $<0.0001$ & 98.02 & $0.0 \pm 0.0$ \\
\hline
\end{tabular}

Abbreviations: na not available, SD standard deviation

$>0.22$ ) and every fluralaner-treated group had significantly fewer ticks than the untreated control group (Table 2). No adverse event was observed in any treated dog.

\section{Discussion}

Water immersion had no impact on subsequent acaricidal efficacy, either from immersion $1 \mathrm{~h}$ prior to administration or from immersion 12 to $24 \mathrm{~h}$ after topical fluralaner administration. This outcome may not be surprising, given that topically administered fluralaner is absorbed across the skin and subsequently delivers its acaricidal effect through systemic distribution which would not be affected by water immersion. However, water immersion could reduce subsequent efficacy of a systemic active ingredient, for example: immersion before treatment could reduce transdermal absorption by increasing product run off or drip off at the application site. Water immersion post-treatment could wash active ingredient away from the application site with consequent reduction in plasma levels through decreased transdermal active ingredient absorption. These results show there was no efficacy reduction following water immersion at the time point tested and is an indication that there was little or no loss of active ingredient from the administration site.

Tick challenges in this study were administered 7 days after treatment and lasted for $24 \mathrm{~h}$. The pharmacokinetic (PK) pattern of absorbed fluralaner after topical administration to dogs at the minimum clinical dose shows that 7 days is just prior to the expected $C_{\max }$ plateau; therefore, a $24 \mathrm{~h} R$. sanguineus (s.l.) challenge at this time provides relevant data showing that sufficient fluralaner was absorbed to provide effective systemic acaricidal protection [2]. A $24 \mathrm{~h}$ tick challenge time was used rather than a $48 \mathrm{~h}$ challenge time as in the previous water immersion study [3] to increase the severity of the challenge. Dogs in this 
study were not treated with shampoo as in the previous study [3], and intentional shampoo use within $72 \mathrm{~h}$ after topical fluralaner administration is not recommended.

Water immersion $1 \mathrm{~h}$ before treatment is consistent with the product prescribing information [1]. The high acaricidal efficacy observed in dogs immersed before treatment indicates that a dog that swims shortly before topical fluralaner administration is not likely to experience a subsequent reduction in acaricidal efficacy.

\section{Conclusions}

Water immersion of dogs $1 \mathrm{~h}$ before or more than $12 \mathrm{~h}$ after topical fluralaner treatment did not reduce subsequent systemic acaricidal efficacy.

\section{Acknowledgements}

The authors are sincerely grateful to the Research Operations team and to all the monitors who ensured adherence to GCP standards.

\section{Funding}

The study was sponsored by Merck Animal Health, Madison, NJ, USA

\section{Availability of data and materials}

The datasets generated and/or analyzed during the current study are not publicly available because they are confidential commercial information, but are available from the corresponding author on reasonable request.

\section{Authors' contributions}

$H D, L M$ and RA authored the study design, monitored the study and interpreted the results. All authors revised and approved the final manuscript.

\section{Ethics approval}

This study was approved by the Clinvet International IACUC.

\section{Consent for publication}

Not applicable.

\section{Competing interests}

$\mathrm{HD}$ and RA are employees of MSD Animal Health.

\section{Publisher's Note}

Springer Nature remains neutral with regard to jurisdictional claims in published maps and institutional affiliations.

\section{Author details}

${ }^{1}$ MSD Animal Health, Intervet Deutschland GmbH, Feldstraße 1a, 85716 Unterschleißheim, Germany. ${ }^{2}$ Clinvet International, Uitzich Road, Bainsvlei, Bloemfontein 9338, South Africa. ${ }^{3}$ Merck Animal Health, 2 Giralda Farms, Madison, NJ, USA.

Received: 18 July 2017 Accepted: 17 September 2017

Published online: 25 September 2017

\section{References}

1. European Commission: Community register of veterinary medicinal products, Product information Bravecto, Annex 1 Summary of product characteristics. 2017. http://www.ema.europa.eu/ema/index.jsp?curl=pages/ medicines/veterinary/medicines/002526/vet_med_000285.jsp\&mid= WC0b01ac058001fa1c.

2. Kilp S, Ramirez D, Allan MJ, Roepke RKA. Comparative pharmacokinetics of fluralaner in dogs and cats following single topical or intravenous administration. Parasit Vectors. 2016;9:296.

3. Taenzler J, Gale B, Zschiesche E, Roepke RKA, Heckeroth AR. The effect of water and shampooing on the efficacy of fluralaner spot-on solution against Ixodes ricinus and Ctenocephalides felis infestations in dogs. Parasit Vectors. 2016;9:233.
Submit your next manuscript to BioMed Central and we will help you at every step:

- We accept pre-submission inquiries

- Our selector tool helps you to find the most relevant journal

- We provide round the clock customer support

- Convenient online submission

- Thorough peer review

- Inclusion in PubMed and all major indexing services

- Maximum visibility for your research

Submit your manuscript at www.biomedcentral.com/submit 